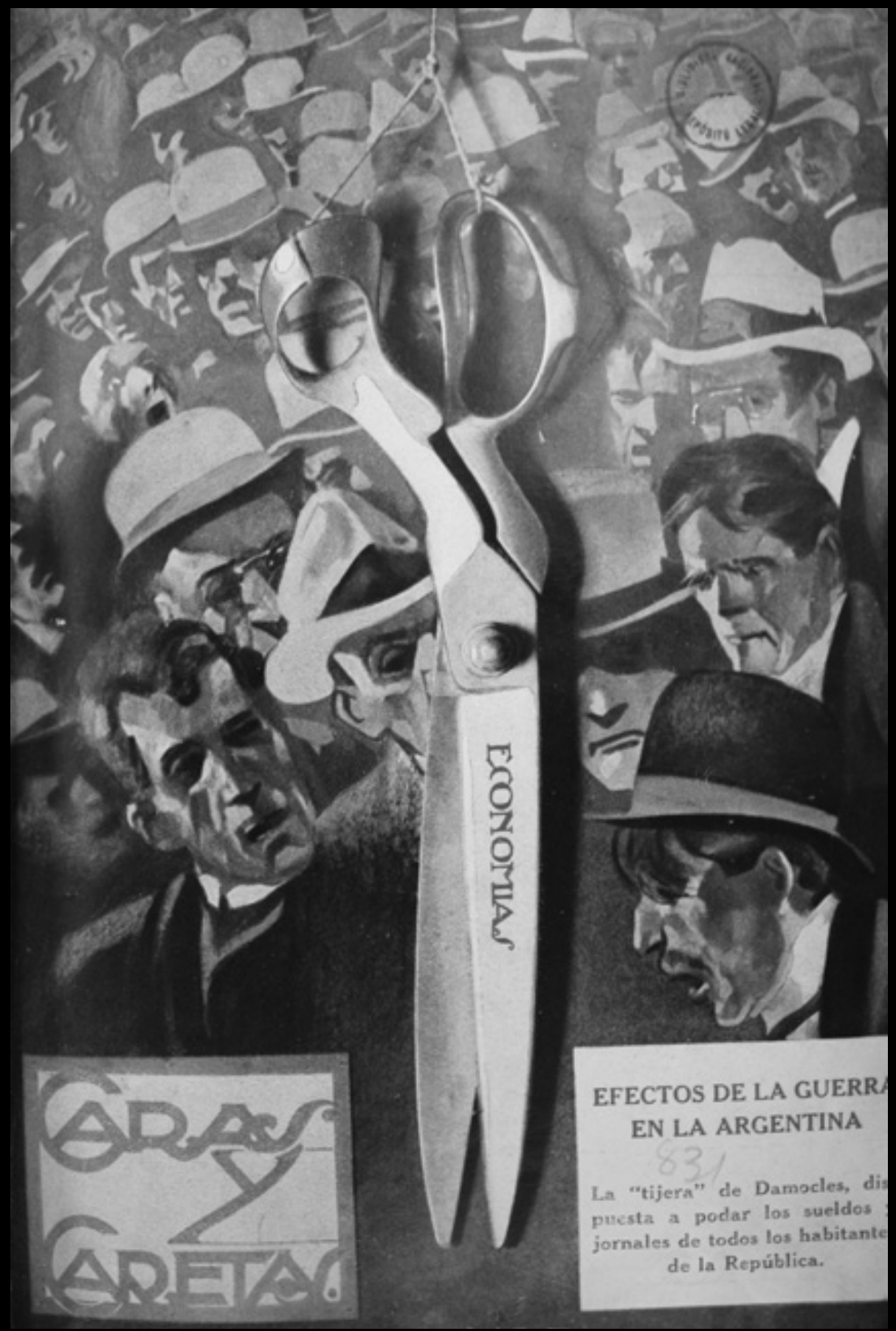

«Efectos de la guerra en Argentina», portada de la revista Caras y Caretas, no. 831, 5 de septiembre de 1914. Dibujo de Juan Carlos Alonso. 


\section{La prensa de Buenos Aires ante «el suicidio de Europa». El estallido de la Gran Guerra como una crisis civilizatoria y el resurgimiento del interrogante por la identidad nacional The press in Buenos Aires in the face of "the suicide of Europe." The outbreak of the Great War as a civilizing crisis and the resurgence of a national identity issue A imprensa de Buenos Aires ante «o suicídio de Europa». O estouro da Grande Guerra como uma crise civilizatória e o ressurgimento do interrogante pela identidade nacional}

Emiliano Gastón Sánchez

CONICET, UNTREF, UBA

(Buenos Aires, Argentina)

emilianosanchez81@hotmail.com

\section{Resumen}

Este artículo analizará, a la luz de un conjunto de publicaciones periódicas de Buenos Aires, la emergencia de una serie de reflexiones y representaciones sobre el papel de Argentina frente a los inicios de la Gran Guerra. Junto a los diferentes alineamientos, basados en la empatía con algunos de los países contendientes, durante los meses iniciales del conflicto emergerá paralelamente y en tensión, aunque de forma menos taxativa, una progresiva toma de distancia respecto al magisterio europeo y un afianzamiento de la identidad nacional. De este modo, el desconcierto producido por el estallido de la guerra en Europa desata una serie de reflexiones acerca del lugar que ocupa Argentina en el mundo y origina un progresivo reajuste en los proyectos de construcción de la identidad nacional que tomaban como modelos civilizatorios a algunos de los países que ahora se hallaban involucrados en una contienda bélica de grandes dimensiones.

\section{Palabras clave}

prensa periódica; Gran Guerra; Buenos Aires; crisis civilizatoria; cuestión nacional; historia cultural de la prensa

\section{Abstract}

This article will analyze the emergence of a series of reflections and representations of the role of Argentina in the face of the beginnings of the Great War, using a set of journals from Buenos Aires. Along with different alignments based on the empathy with some disputing countries during the early months of the conflict, it will emerge at the same time and in tension, although in a less emphatic way, a progressive distancing from the European education and the reinforcement of a national identity. Thus, the confusion caused by the outbreak of the war in Europe triggered a series of reflections on the place Argentina had in the world. It caused a gradual adjustment of national identity construction projects which considered some of the countries involved in a large military conflict as civilizational models.

\section{Keywords}

periodical press; Great War; Buenos Aires; civilizational crisis; national issue; cultural history of the press

\section{Resumo}

Este artigo analisa, à luz de um conjunto de publicações periódicas de Buenos Aires, a emergência de uma série de reflexões e representações sobre o papel da Argentina face aos inicios da Grande Guerra. Junto aos diferentes alinhamentos, baseados na empatia com alguns dos países contendores, durante os meses iniciais do conflito emergirá paralelamente e em tensão, aliás que de forma menos taxativa, um distanciamento progressivo no que diz respeito ao magistério europeu e um reforço da identidade nacional. Deste modo, o desconcerto produzido pela eclosão da guerra em Europa desata uma série de reflexões acerca do lugar que ocupa a Argentina no mundo e origina um progressivo reajuste nos projetos de construção da identidade nacional que tomavam como modelos civilizatórios a alguns países agora envolvidos na contenda bélica de tamanhas dimensões.

\section{Palavras-chave}

imprensa periódica; Grande Guerra; Buenos Aires; crise civilizatória; assunto nacional; história cultural da imprensa 
Los estrechos vínculos económicos que mantenía con el Imperio británico, la profunda influencia política y cultural ejercida por Francia y la abrumadora presencia de inmigrantes europeos radicados en el país, hicieron que en Argentina, y en particular en Buenos Aires, las noticias sobre el estallido de la Gran Guerra tuvieran una gran resonancia. Desde el comienzo del conflicto, la inmensa mayoría de la opinión pública porteña manifestó abiertamente sus simpatías por la Triple Entente a decir verdad por Francia y, en mucha menor medida, por Inglaterra. En su dimensión más inmediata, estos alineamientos estuvieron, al menos en parte, condicionados por la procedencia de la información, la cual estaba sometida a fuertes manipulaciones en favor de los aliados gracias al monopolio de la agencia Havas sobre el mercado sudamericano de comunicaciones y al control por parte de las compañías británicas de cables submarinos de los principales medios de transmisión de la información. Sin embargo, más allá de la capacidad para formar opinión que pudo haber tenido la información procedente de Europa, los diferentes alineamientos de la opinión pública local no pueden comprenderse únicamente por la manipulación informativa y la tendencia de las noticias internacionales que publicaban los diarios de Buenos Aires.

Frente al nuevo escenario europeo marcado por el inicio de la guerra, emergieron un conjunto de problemas derivados de mirar a una serie de «otros» que han venido oficiando de referentes culturales y como modelos de sociedad -construidos incluso, frecuentemente, como faros prescriptivos- los cuales aparecen ahora enfrentados, desatando una verdadera ruptura civilizatoria. Mirada desde Argentina, la Primera Guerra Mundial desencadena una serie de inconvenientes para una cultura nacional que tradicionalmente se miraba de forma especular con Europa y que ahora debe redefinirse a partir de una imagen trágica que el Viejo Mundo le devuelve tras haber sido durante años el modelo paradigmático a seguir para las élites locales. Es por ello que diferentes sectores de la opinión pública porteña y de la prensa se vieron llamados a tomar partido por ciertas naciones en pugna, es decir, a adscribir a determinados modelos nacionales considerados afines o en los cuales debería nutrirse la cultura argentina.
Sin embargo, junto a esos posicionamientos basados en la empatía con ciertos países contendientes emergerá paralelamente y en tensión, aunque de forma menos taxativa, una progresiva toma de distancia respecto al magisterio europeo y un afianzamiento de la identidad nacional. De este modo, el desconcierto producido por la guerra europea desata también una serie de reflexiones acerca del lugar que ocupa Argentina en el mundo y origina un progresivo reajuste en los proyectos de construcción de la identidad nacional que tomaban como modelos civilizatorios a algunos de los países que ahora se hallaban involucrados en una contienda bélica de grandes dimensiones. En ese juego, entre la herencia simbólica recibida y la activa resignificación local, la prensa porteña descifrará los contornos de la Gran Guerra, al tiempo que abona nuevas reflexiones sobre la identidad y la cultura nacional conformadas al calor de las fricciones propias del vertiginoso proceso de modernización económica y social iniciado a partir de 1880 .

El análisis de las estrategias interpretativas y de los diferentes alineamientos de la prensa porteña durante los meses iniciales del conflicto permite afirmar que la Primera Guerra Mundial constituyó un acontecimiento catalizador del interrogante sobre la identidad nacional en Argentina pues, al tiempo que dinamiza el juego de selección de afinidades con lo europeo, la consternación producida por el estallido de la guerra en el Viejo Continente reabre el debate sobre los alcances y las potencialidades de la cultura nacional. Las respuestas ensayadas por la prensa porteña a los interrogantes sobre la auténtica identidad nacional y la evaluación de los modelos a seguir en Europa luego del inicio del conflicto bélico permitieron la reafirmación de un nacionalismo cosmopolita que, sin rechazar de plano la herencia de la cultura europea, se autorreconoce en la experiencia pacífica de la Argentina posterior a la conformación del Estado nacional en 1880. Esas características lo ubican más próximo del llamado «nacionalismo del Centenario» que de los movimientos nacionalistas que florecerán en Argentina a partir de la primera posguerra.

El objetivo de este artículo es analizar, desde la perspectiva de la historia cultural de la prensa, la emergencia de un conjunto de reflexiones 
y representaciones sobre el papel de Argentina ante el inicio de la Gran Guerra, tomando para ello un amplio conjunto de publicaciones periódicas de Buenos Aires durante la fase inicial del conflicto, comprendida entre el asesinato del archiduque Francisco Fernando en Sarajevo, el 28 de junio de 1914, hasta finales de diciembre de 1914. Esta delimitación del objeto de estudio se justifica por varias razones. En primer lugar, por una cuestión cuantitativa: durante esos meses iniciales del conflicto los periódicos porteños publicaban diariamente una enorme cantidad de información relacionada con la guerra que constituía la gran novedad del momento. En segundo lugar, en ese breve periodo es posible constatar la existencia de una serie de núcleos temáticos importantes, como la querella sobre las responsabilidades por el estallido de la guerra, los primeros alineamientos de la opinión pública porteña y la invasión alemana de Bélgica, los cuales influyeron y enmarcaron las reflexiones sobre la identidad nacional que se produjeron al calor de los meses iniciales del conflicto. Y, en tercer lugar, la opción de un corte en la periodización hacia finales de 1914 responde también a una percepción propia de los contemporáneos. Concebida inicialmente como una guerra breve, más cercana a las campañas decimonónicas que a la guerra industrial de masas en la que se transformará luego, los altos mandos militares y los líderes políticos de todas las naciones combatientes proyectaban pasar la «Navidad en casa». Lejos de esas aspiraciones, el fin de 1914 muestra un panorama mucho más sombrío marcado por la emergencia de un nuevo tipo de combate, la guerra de trincheras, que nadie sabe a ciencia cierta cómo resolver. Ese panorama, que abre a un nuevo periodo de la guerra marcada por el estancamiento de los frentes que se tradujo en una guerra de posiciones, sobre todo en el frente occidental, también se hace presente en los balances de fin de año de la prensa porteña y abre una nueva etapa en la cobertura mediática del conflicto.

Esa delimitación temática y cronológica responde también a una apreciación sobre las investigaciones precedentes que han estudiado el impacto de la guerra sobre la identidad nacional. En los últimos años, la cuestión sobre la crisis identitaria que trajo aparejada la contienda europea ha sido analizada por algunas de las investigaciones que han comenzado a sustraer el estudio de las repercusiones ocasionadas por la Gran Guerra en Argentina de sus ámbitos historiográficos más tradicionales, como son la historia económica y los avatares sobre la política exterior durante los años del conflicto ${ }^{1}$. Sin embargo, dichas indagaciones no han insistido lo suficiente sobre la importancia de la fase inicial de las repercusiones del conflicto en la opinión pública porteña y en la prensa periódica de gran tirada. En su artículo sobre la prensa argentina y brasileña frente a la Gran Guerra, Olivier Compagnon afirma que, durante los meses iniciales del conflicto, la prensa de Buenos Aires otorgó un lugar secundario a la cobertura de la conflagración europea, abocándose a otros acontecimientos como la muerte de algunas figuras rutilantes de la política local, como el presidente Roque Sáenz Peña o el ex presidente Julio Argentino Roca y a los vaivenes políticos de la Revolución Mexicana ${ }^{2}$.

Sin embargo, basta con hojear los principales diarios y revistas de Buenos Aires para constatar que el inicio de la Gran Guerra fue un asunto neurálgico para la prensa local y que, si bien los

1 Para una mirada de conjunto acerca de la historiografía sobre las repercusiones de la Gran Guerra en Argentina, me permito remitir a Emiliano Gastón Sánchez, «Ecos argentinos de la contienda europea. La historiografía sobre la Gran Guerra en la Argentina», Políticas de la Memoria. Anuario de investigación e información del CeDInCI, no. 13 (verano 2012/13): 163-169.

2 «Lorsque la guerre éclate en Europe au cours de l'été 1914, on pourrait presque dire qu'elle passe inaperçue tant on peine à trouver des relations de la mobilisation et des premiers combats. Même la bataille de la Marne, premier tournant militaire important qui rompt l'avance allemande vers Paris en septembre, n'est évoquée que très marginalement ; quelques brèves, çà et là, évoquent ce que l'on nomme fréquemment 'les événements européens'. L'actualité argentine est dominée pendant tout le mois d'août par le décès brutal du président de la République Roque Sáenz Peña, tandis que les derniers développements de la Révolution mexicaine [...] occupent l'essentiel des rubriques internationales dans la presse des deux pays ». Cf. Olivier Compagnon, «'Si loin, si proche...' La Première Guerre mondiale dans la presse argentine et brésilienne», en L'envers de la médaille. Guerres, témoignages et représentations, ed. Jean Lamarre y Magali Deleuze (Québec: Les Presses de I'Université Laval, 2007), 79. La misma idea es reiterada en su reciente libro («La presse, en effet, n'accorde encore qu'une place secondaire au traitement d'un conflit dont la plupart des observateurs imaginent qu'il sera bref» y «l'étude de la presse ne révèle pas une véritable mobilisation des sociétés pendant les premières semaines du conflit»), insistiendo en que, por entonces, la actualidad americana ocupaba un rol central en la prensa de Argentina y Brasil. Cf. Olivier Compagnon, L'adieu à l'Europe. L'Amérique latine et la Grande Guerre (Argentine et Brésil, 1914-1939) (París: Fayard, 2013), 35 y 64. 
acontecimientos señalados por Compagnon tuvieron su lugar en las páginas de los diarios porteños, su influencia duró solo unos días en el caso de los ex mandatarios o fue más bien intermitente, sobre todo en la cobertura del conflicto mexicano. Lejos de esta interpretación, es posible sostener que la conmoción que produjo el estallido de la guerra en la prensa periódica de Buenos Aires fue tan grande que incluso afectó apartados y secciones que a priori no estarían interesadas en ella como, por ejemplo, las secciones sociales y las columnas de las revistas ilustradas orientadas al público femenino, transformándose en el tema excluyente de la prensa local durante los meses posteriores ${ }^{3}$.

La escasa trascendencia otorgada a los meses iniciales del conflicto contrasta con la enorme atención que ha suscitado en la historiografía local la crisis política y diplomática de 1917, que constituye uno de los puntos más álgidos de las repercusiones de la Primera Guerra Mundial en Argentina ${ }^{4}$. En dos artículos publicados en 2008, María

3 Véase, a modo de ejemplo, «Informaciones oficiales. Familias argentinas en Europa», La Nación [Buenos Aires], 15 de agosto, 1914, 9; «Tribulaciones de los argentinos en Europa», La Nación [Buenos Aires], 8 de septiembre, 1914, 9; Carmen S. de Pandolfini, «Charla femenina», Mundo Argentino [Buenos Aires], 19 de agosto, 1914 y 26 de agosto, 1914, s/p. Incluso Martín Gil, célebre divulgador de la astronomía y pronosticador del tiempo, asiduo colaborador del diario La Nación, encabezó sus vaticinios sobre un posible eclipse solar que tendría lugar en Europa con alusiones a la guerra: «Escribir en estos momentos sobre cuestiones que no huelan a pólvora o estopa, a bombardeos, incendios y degüellos, es decir, ocuparse de la real bestia humana desatada aunque no hambrienta todavía es perder tiempo y tinta» y en una inflexión discursiva, que analizaremos en detalle más adelante, ironizaba: «¿Qué podríamos decir nosotros de todo esto, nosotros los salvajes de Sudamérica ante aquellos pueblos de razas absolutamente superiores como lo están demostrando y algunas de ellas, representantes de Dios en la tierra y a quien invocan pretendiendo asociarse a él para degollar y quemar con toda desenvoltura? Pues no podía negarse que el bombardeo de una ciudad de 100.000 almas como Belgrado y el incendio de otras, es un acto de cultura ultrasuperior y de elevadísima moral cristiana». Martín Gil, «Impresiones», La Nación, 17 de agosto, 1914, 5.

4 La llamada «crisis de 1917» fue el resultado de una drástica combinación de factores externos e internos en un breve periodo de tiempo. En febrero de ese año, los Estados Unidos rompieron relaciones diplomáticas con el Imperio alemán y en abril ingresaron en la guerra como respuesta al restablecimiento de la guerra submarina ilimitada. Esta decisión norteamericana trajo aparejada fuertes presiones diplomáticas para que los países del continente adoptaran la misma postura, aunque en el caso argentino dichas presiones no lograron modificar el rumbo de la política neutralista del presidente Hipólito Yrigoyen. La gravedad de la situación se incrementó a partir de abril de 1917 a raíz del hundimiento por parte de los submarinos alemanes de varios buques de bandera argentina: el 4 de abril fue hundido el Monte Protegido, el 6 de
Inés Tato ha estudiado las diferentes interpretaciones sobre «la argentinidad» $y$ sus deberes que, de manera más o menos explícita, subyacían en las movilizaciones y los debates protagonizados por la sociedad argentina durante la crisis de 1917. A juzgar por los argumentos esgrimidos por la autora, esa coyuntura constituye un momento clave para el estudio de las repercusiones de la guerra en Argentina ya que,

[...] aunque tempranamente los intelectuales y algunos medios de prensa como el vespertino Crítica se posicionaron con contundencia frente a la guerra en función de simpatías por uno u otro bando, en la opinión pública no se generaron identidades políticas definitivas ni ásperos debates hasta abril de $1917^{5}$.

Ahora bien, en su análisis sobre la evolución del nacionalismo en el seno de la opinión pública argentina, la prensa periódica ocupa un lugar marginal, limitado a delinear un estado del campo periodístico mediante una taxonomía estática y reduccionista que distingue entre la prensa «aliadófila» y «germanófila» o, según los términos utilizados durante la crisis, «neutralista» $y$ «rupturista» ${ }^{6}$. Si bien

junio, el Oriana y el 22 de junio el Toro. Ese clima de hostilidad originó una fuerte polarización de la opinión pública entre «neutralistas» $\mathrm{y}$ «rupturistas» que se disputaban las calles de la ciudad mediante movilizaciones que buscaban forzar el ingreso de Argentina en la guerra o mantener la neutralidad. Mientras el gobierno argentino gestionaba las reclamaciones correspondientes por vía diplomática, otro incidente marcó la última escalada de la crisis: el affaire Luxburg. En septiembre, el gobierno de los Estados Unidos difundió una serie de telegramas cifrados del ministro alemán en Argentina, el conde Karl Graf von Luxburg, que iban dirigidos al káiser Guillermo II. En ellos se refería en términos despectivos al presidente Yrigoyen y a su ministro de Relaciones Exteriores, Honorio Pueyrredon («un notorio asno y anglófilo») y recomendaba a las autoridades alemanas continuar con el hundimiento de los buques argentinos «sin dejar rastros». Obviamente, cuando estos telegramas tomaron estado público, el presidente se vio obligado a entregar los pasaportes al diplomático germano pero aun así mantuvo su decisión de no romper relaciones con Alemania.

5 María Inés Tato, «La disputa por la argentinidad. Rupturistas y neutralistas durante la Primera Guerra Mundial», Temas de historia argentina y americana, no. 13 (2008): 229-230. En análogo sentido, María Inés Tato, «Nacionalismo e internacionalismo en la Argentina durante la Gran Guerra», Projeto História, no. 36 (2008): 51.

6 Siguiendo los clásicos estudios de Raimundo Siepe y Ricardo Weinmann, la autora afirma que «La prensa de alcance nacional también reflejó esa polarización y se alineó explícitamente con los grupos en pugna: El Diario, La Nación, Crítica, La Mañana, La Vanguardia, Plus Ultra, Nosotros, La Argentina y Última Hora fueron defensores de la causa de la ruptura con los imperios centrales, en tanto, La Época, La Unión y la Revista de Derecho, Historia y Letras eran partidarios de la neutralidad. La Prensa y La Razón, por su parte, eran moderadamente favorables a los Aliados, aunque también oficiaban de tribuna de opiniones independientes y de reconocidos neutralistas, 


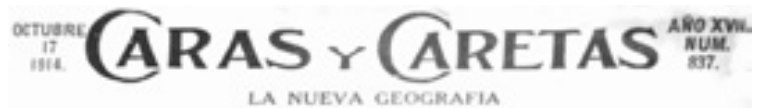

LA NUEVA GEOGRAFIA

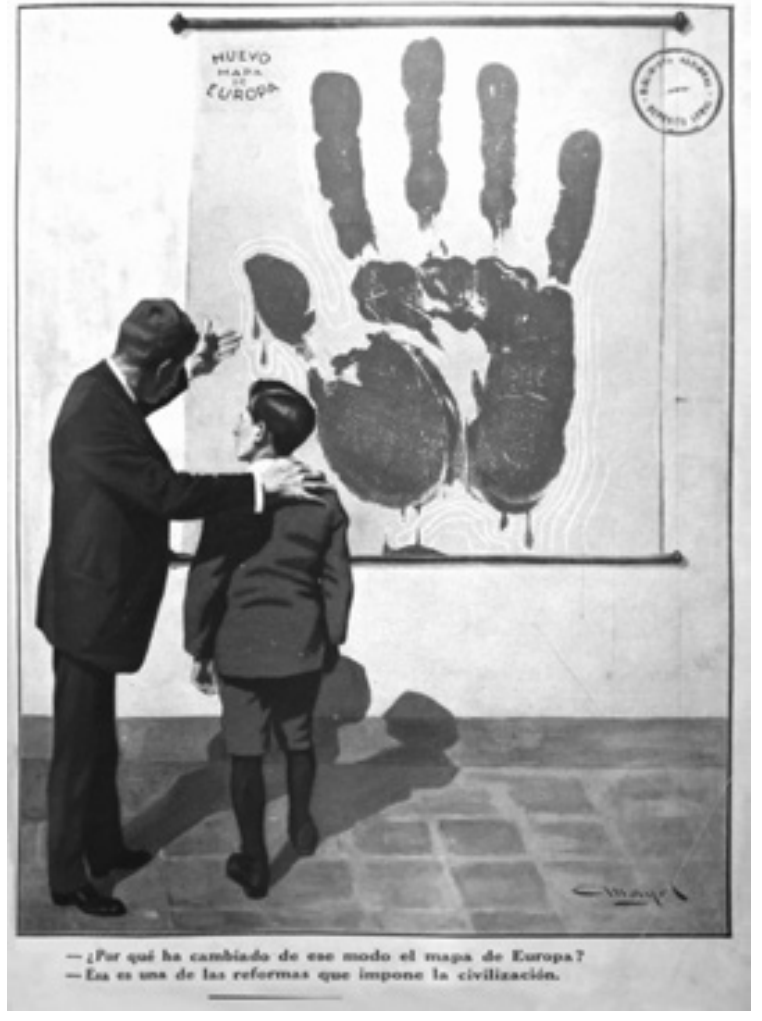

Figura 1. Crisis de civilización. Caras y Caretas 17, no. 837. 17 de octubre de 1914

es cierto que un mapa de los posicionamientos puede resultar de gran utilidad para el lector, su trazado torna opacas algunas diferencias importantes. Las publicaciones periódicas son por definición emprendimientos colectivos y constituyen productos culturales complejos, que responden a varias voluntades con prácticas discursivas singulares y que utilizan distintos códigos expresivos, textuales y visuales, por lo cual discursos diferentes e incluso antagónicos pueden coexistir en las páginas de una misma publicación. Es por esto que un análisis sobre las representaciones de la Primera Guerra Mundial en la prensa periódica de un país neutral como Argentina debería evitar la tendencia al etiquetamiento estático de las posiciones de la prensa ante el conflicto, optando por una mirada de conjunto sobre las publicaciones que permitiera evaluar la compleja coexistencia de discursos

como Estanislao Zeballos, colaborador asiduo del diario de los Paz». Tato, «La disputa», 234. Aunque algo más atento a ciertos matices, Compagnon replica un esquema muy similar aunque apela a otros rótulos para distinguir entre la prensa «aliadófila», «equilibrada»y «germanófila». Compagnon, L'adieu, 66-67. visuales y textuales discordantes e incluso antagónicos, independientemente de una tendencia más o menos evidente en la política editorial del diario o la revista en cuestión.

Pero además, dadas las características específicas que rodearon a dicha crisis, las conclusiones que extrae la autora sobre la discusión en torno a la cuestión nacional son difícilmente extrapolables a otros momentos de la repercusión de la Gran Guerra en Buenos Aires. La excesiva ponderación de esa particular coyuntura de 1917 pierde de vista que el debate en torno a la identidad nacional es concomitante al estallido de la Gran Guerra y que, en el ámbito de la prensa periódica de gran tirada, su alcance incluye una serie de rasgos no contemplados por las investigaciones precedentes.

\section{Un salto al vacío. La Gran Guerra como una fractura civilizatoria y los interrogantes sobre la cuestión nacional}

A mediados de octubre de 1914, la portada principal del semanario Caras y Caretas mostraba un mapa de Europa en el cual las fronteras tradicionales del Viejo Continente habían sido reemplazadas por la figura de una enorme palma de una mano ensangrentada que un padre $o$, tal vez un maestro, le enseñaba a un joven que se hallaba junto a él (Fig. 1). Ante el interrogante del niño sobre el por qué de estos cambios en la geografía de Europa, el mayor le responde: «Esa es una de las reformas que impone la civilización». Esta imagen del dibujante español Manuel Mayol condensaba una serie de sentidos sobre los inicios de la Gran Guerra y, en particular, la puesta en tela de juicio de Europa como el modelo civilizatorio para las futuras generaciones de argentinos, representadas en ese joven de pantalones cortos que observa atento la lección brindada frente al nuevo mapa del Viejo Continente. Pocas semanas antes, una portada de la revista P.B.T. de mediados de septiembre había mostrado a los líderes europeos de los estados beligerantes con los rostros enrojecidos por el resplandor al contemplar un bosque en llamas (Fig. 2). El título elegido por la revista para coronar este dibujo de José Olivella fue «El "foco" de la civilización». A juzgar por la retroalimentación entre el discurso escrito y visual de dicha 
portada, en solo un par de semanas, para un arco importante de la opinión pública de Buenos Aires, Europa se había transformado del foco de la civilización occidental en el foco de un gigantesco incendio que amenazaba con arrasar el mundo entero. Estas dos imágenes condensan una misma idea y una temprana mirada de la prensa porteña frente al estallido de la Gran Guerra como una fractura civilizatoria.

Al mismo tiempo que las páginas de los diarios de Buenos Aires eran inundadas por un conjunto de representaciones, valores y sentidos sobre la Primera Guerra Mundial provenientes de Europa y daban cabida a los diferentes alineamientos con los bandos en disputa, emergieron un conjunto de interpretaciones que veían en la Gran Guerra un verdadero «suicidio de Europa». Esa tendencia discursiva partía de un diagnóstico de la guerra europea como una ruptura civilizatoria puesto que participaban en ella los países que tradicionalmente habían sido considerados como los modelos a seguir para las élites argentinas. En palabras de un anónimo comentarista del diario La Prensa, el estallido de la guerra constituía un «formidable salto en las tinieblas» que torna difícil predecir sus consecuencias pues intervienen en ella las «viejas naciones, maestras de la cultura y guías de la civilización del mundo» ${ }^{7}$. Esa caracterización de la guerra será el punto de partida que posibilitará la emergencia de una serie de críticas a la idea de Europa como el pináculo de la civilización occidental.

Un rasgo central de esa impugnación al lugar ocupado por Europa en el imaginario de las élites y de la opinión pública local fueron las críticas a la idea de progreso como vertebradora de un esquema evolucionista gracias al cual las generaciones sucesivas vivirían siempre en un estadio civilizatorio superior respecto de sus antepasados. En Argentina, desde mediados de 1870 la difusión de ciertas ideologías había posibilitado el desarrollo de una «mentalidad evolucionista» en el seno de la élite intelectual y política ${ }^{8}$. El evolucionismo,

7 «Guerra en el continente europeo», La Prensa [Buenos Aires], 2 de agosto, 1914, 7. También en «La Guerra», Tribuna [Buenos Aires], 6 de agosto, 1914, 2.

8 Para una reconstrucción de los procesos de recepción y apropiación de estas ideas en Argentina véase, Marcelo Montserrat, «La mentalidad evolucionista: una ideología del Progreso», en

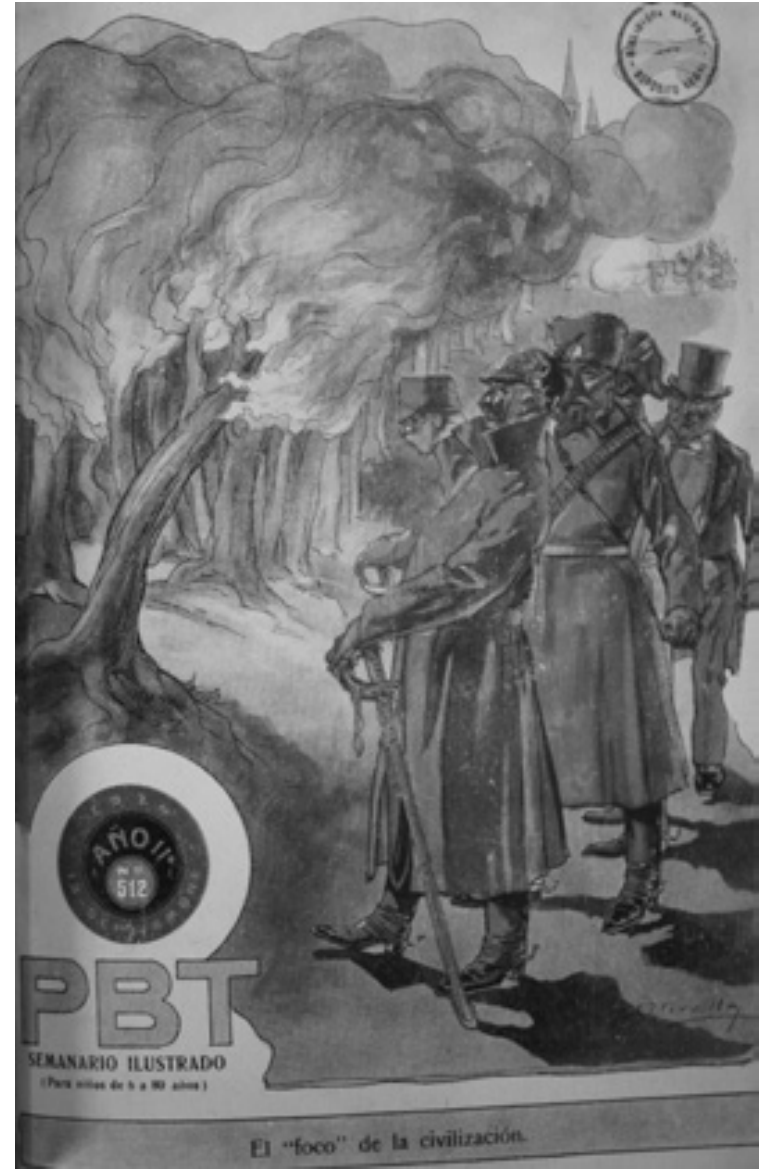

Figura 2. El "foco" de la civilización. PBT, Semanario Ilustrado 11, 512.19 de septiembre de 1914.

tanto en su versión darwiniana como en la variante spenceriana, se convirtió en un elemento central de la cultura argentina del fin de siglo e impregnó de militante progresismo biologicista al positivismo local, brindando un marco a la reflexión histórica, política y social. En ese esquema, el progreso fue considerado como el motor y la última ratio de la historia y, a los ojos de los contemporáneos, la evolución de ciertos indicadores del desarrollo económico y social parecía indicar que Argentina se hallaba en una senda de crecimiento y de progreso indefinido.

La Argentina del Ochenta al Centenario, comp. Gustavo Ferrari y Ezequiel Gallo (Buenos Aires: Sudamericana-UTDT, 1980), 785-818; Gregorio Weinberg, La ciencia y la idea de progreso en América Latina, 1860-1930 (Buenos Aires: FCE, 1998) y Oscar Terán, Vida intelectual en el Buenos Aires fin-de-siglo (1880-1910). Derivas de la «cultura científica» (Buenos Aires: FCE, 2008 [original 2000]). Sobre su profusa influencia en la literatura argentina del siglo xIx puede consultarse Sandra Gasparini, Espectros de la ciencia. Fantasías científicas de la Argentina del siglo xIX (Buenos Aires: Santiago Arcos, 2012). 
Es por ello que, como ha señalado Tulio Halperín Donghi, para las élites argentinas el estallido de la Gran Guerra representó una

[...] disolución de esa visión lineal y ascendente del proceso histórico que en el siglo anterior había marcado con su signo la fe colectiva de una Europa en ascenso y, en la Argentina se había encarnado en esa otra fe nacional que había alcanzado su formación más elocuente en la obra histórica de Mitre 9 .

En sentido análogo, para un importante espectro de la prensa porteña la Primera Guerra Mundial representó una ruptura respecto de ese legado europeo, y esa puesta en duda de la linealidad del progreso estuvo íntimamente asociada con una temprana percepción de un agotamiento del ciclo civilizatorio europeo, que coincidía en señalar sus raíces en la destrucción de los valores morales ocasionada por los placeres mundanos de la cultura materialista y secular de las sociedades burguesas ${ }^{10}$.

En ese nuevo clima de ideas producido por el desencadenamiento de la guerra y a partir de su interpretación como un agotamiento del ciclo civilizatorio europeo, emergerán una serie de reflexiones sobre la cuestión nacional. Observada desde la distancia y al amparo de la neutralidad decretada por el gobierno argentino, la Primera Guerra Mundial desencadenó un conjunto de problemas para una cultura nacional en formación que tradicionalmente se miraba de forma especular con Europa, obligada a redefinirse a partir de una imagen trágica que el Viejo Mundo le devuelve tras haber sido por años el modelo paradigmático a seguir para las élites locales ${ }^{11}$. De esta manera, el inicio de la guerra

9 Tulio Halperin Donghi, Vida y muerte de la República verdadera (1910-1930) (Buenos Aires: Ariel, 1999), 66.

10 Ante el estallido de la guerra, el diario La Mañana afirmaba: «Europa liquida su era civilizadora, su era benéfica de trabajo y justicia, y se entrega a una alucinación brutal de hundimiento. Una larga subversión de valores morales ha traído, con el relajamiento espiritual, la exaltación de la fuerza exclusiva, y apagado el genio creador y pacífico, se desploma en esa conflagración cuyo resultado posible es tan obscuro y expone al continente europeo al predominio de los elementos subalternos, que han desencadenado la catástrofe, los elementos de la sordidez material y de la potencia bruta». «La guerra», La Mañana [Buenos Aires], 2 de agosto, 1914, 1.

11 Luego del ingreso de Inglaterra en el conflicto bélico, el 4 de agosto de 1914, Argentina declaró la «más estricta neutralidad» frente al estado de guerra entre «naciones amigas». «Decreto declarando la neutralidad de la República en el estado de guerra entre Austria-Hungría, Servia, Rusia, Alemania, Inglaterra, Francia trajo aparejado también una inquietud sobre la identidad y la cultura nacional que se tradujo en una serie de reflexiones sobre el legado del magisterio europeo en Argentina.

En rigor, ese interrogante sobre la naturaleza de la cultura nacional y los destinos de la nación no era novedoso, sino que, por el contrario, formaba parte del sentido común de las élites argentinas desde 1880. De hecho, en las imágenes y los discursos activados a partir del estallido de la Gran Guerra es posible verificar un retorno a varios de los temas que marcaron las discusiones del llamado «nacionalismo del Centenario». En Argentina, este sintagma hace referencia a un tipo de nacionalismo que es ante todo liberal y que rechaza una idea de la nacionalidad centrada exclusivamente en la pertenencia a una cultura en común y, por ende, orientado hacia el pasado. Lejos de ello, postulaba que la elaboración de una cultura nacional debe abrirse hacia el futuro y anclar su construcción en diferentes aspectos específicos del proceso histórico argentino como, por ejemplo, la inmigración masiva ${ }^{12}$. Sin embargo, a diferencia del clima autocelebratorio que acompañó los festejos de 1910, cuando Argentina cotejaba orgullosa sus progresos con los de Europa, luego del estallido de la guerra para un amplio sector de la opinión pública porteña el Viejo Continente deja de ser el modelo paradigmático a seguir.

Probablemente José Ingenieros fue uno de los intelectuales argentinos que mejor expresó ese doble movimiento de diagnóstico de la Gran Guerra como una fractura civilizatoria acompañado por un desplazamiento temático hacia «lo nacional». Partiendo de una noción de decadencia y de un agotamiento del ciclo civilizatorio europeo, comenzó sus indagaciones sobre lo que él

y Bélgica», en Ministerio de Relaciones Exteriores y Culto, Argentina, El libro azul. Documentos y actos de gobiernos relativos a la guerra en Europa (Buenos Aires: Establecimiento Gráfico Enrique L. Frigueiro, 1919), 4-6. El texto del decreto fue reproducido por casi todos los diarios porteños.

12 Véase Carlos Payá y Eduardo Cárdenas, El primer nacionalismo argentino en Manuel Gálvez y Ricardo Rojas (Buenos Aires: Peña Lillo, 1978); Lilia Ana Bertoni, Patriotas, cosmopolitas y nacionalistas. La construcción de la nacionalidad argentina a fines del siglo xIX (Buenos Aires: FCE, 2001); Fernando Devoto, Nacionalismo, fascismo y tradicionalismo en la Argentina moderna. Una historia (Buenos Aires: Siglo xxI, 2006), 47-119 y María Teresa Gramuglio, Nacionalismo y cosmopolitismo en la literatura argentina (Rosario: EMR, 2013): 69-205. 
denominaba la «argentinidad» en una serie de artículos publicados en la revista Caras y Caretas entre agosto de 1914 y julio de $1915^{13}$. En su célebre escrito «El suicidio de los bárbaros», publicado en Caras y Caretas el 22 de agosto de 1914, Ingenieros brindaba una particular interpretación de la guerra como una crisis civilizatoria. En ella llama poderosamente la atención el alcance del término «bárbaro» que comprende y abarca a toda la cultura europea y a lo largo del texto no existe ningún indicio que permita exceptuar de esta condición a las dos naciones que más habían influenciado a las élites argentinas, Francia e Inglaterra. Es por ello que esta primera lectura de Ingenieros sobre la Gran Guerra constituye una importante fisura en su modelo eurocéntrico como paradigma histórico-cultural que, si bien no llegó a conformar un decidido antieuropeísmo, abonó una representación del estallido de la guerra como el agotamiento del ciclo civilizatorio europeo ${ }^{14}$.

13 La activa presencia de Ingenieros en uno de los medios gráficos más populares de Argentina constituye un momento muy particular de su itinerario intelectual marcado por el regreso al país a fines de julio de 1914 tras permanecer por más de tres años en un exilio autoimpuesto en Europa que lo obliga a un progresivo restablecimiento de sus redes intelectuales y a la búsqueda de nuevos espacios de inserción en el campo intelectual argentino. Para una descripción más detallada véase Oscar Terán, José Ingenieros: pensar la nación. Antología de textos (Buenos Aires: Alianza, 1986), 57-72. Durante los años de la Primera Guerra Mundial, Ingenieros se sumergirá en una intensa labor organizativa de la cultura nacional mediante dos grandes proyectos intelectuales: la Revista de Filosofía, Cultura, Ciencias y Educación, aparecida en 1915 y la puesta en marcha de su proyecto editorial, La Cultura Argentina. Para un análisis de estos emprendimientos véase el estudio introductorio de Luis Alejandro Rossi, «Los proyectos intelectuales de José Ingenieros desde 1915 a 1925: la crisis del positivismo y la filosofía en la Argentina», en la edición facsimilar de la Revista de Filosofía, Cultura - Ciencias - Educación (Bernal: unoui, 1999), 1362 y Fernando Degiovanni, «Nacionalismo de mercado y disidencia cultural: La cultura argentina de Ingenieros», en Los textos de la patria. Nacionalismo, políticas culturales y canon en la Argentina (Rosario: Beatriz Viterbo, 2007), 215-320.

14 «Tuvo sus glorias; las admiramos. Tuvo sus héroes; quedan en la historia. Tuvo sus ideales: se cumplieron». José Ingenieros, «El suicidio de los bárbaros», Caras y Caretas, no. 829 (22 de agosto, 1914). Posteriormente, Ingenieros operará una reformulación de esta primera posición frente a la guerra. Durante la crisis de 1917, la Revista de Filosofía tendrá un fugaz momento «aliadófilo» y en su número de mayo reproducirá casi integro el célebre artículo de Leopoldo Lugones «Neutralidad imposible», publicado originalmente en el diario La Nación, el 7 de abril de 1917. Luego, la Revolución Rusa, la Reforma Universitaria y la Semana Trágica de 1919 serán las causas con las que se identificará. En su conferencia «Ideales viejos e ideales nuevos», dictada el 8 de mayo de 1918 en Rosario, afirmaba: «Mis simpatías están con Francia, Bélgica, con Italia, con Estados Unidos, porque esas naciones están más cerca de los ideales nuevos y más reñidas de los ideales viejos. Mis
De un fuerte tono prescriptivo, el texto no solo establece un dictamen sobre la cultura europea y el fin de su potencialidad ético-civilizatoria, también señala cuáles son los caminos que Argentina deberá tomar de cara al futuro, lo que habilita una reafirmación de la identidad nacional que será una de las preocupaciones más acuciantes de este periodo de su obra. El conflicto europeo funciona aquí como una suerte de pretexto para reexaminar el proceso de modernización controlado por las élites locales desde 1880 y la labor de ciertas figuras como Bernardino Rivadavia, Juan B. Alberdi, Domingo F. Sarmiento y Florentino Ameghino $^{15}$. Sin embargo, más allá de las particularidades de este escrito ya clásico, si se lo inserta en el conjunto de la prensa periódica porteña, su originalidad se torna mucho menos evidente. Por el contrario, la reapertura del debate sobre la cuestión nacional, fruto de un diagnóstico de los inicios de la Gran Guerra como una crisis civilizatoria, fue un lugar común bastante extendido en la prensa porteña.

Una de las aristas más destacadas de ese renovado debate sobre «lo nacional» estaba directamente relacionada con la cuestión económica. Los principales diarios de Buenos Aires tenían muy en claro que, independientemente de sus simpatías

simpatías, en fin, están con la Revolución Rusa...». Editada como folleto, entre otros, por la Biblioteca Popular de la Universidad Libre de Israel en 1918 y luego incluida en su libro Los tiempos nuevos. Reflexiones optimistas sobre la guerra y la revolución (Buenos Aires: Cuneo, 1921).

15 Las intervenciones posteriores a este diagnóstico de la Gran Guerra como una ruptura civilizatoria apuntan a cimentar los pilares de la nueva cultura argentina iluminada a partir de la crisis del modelo europeo. De esta manera, los escritos de José Ingenieros en Caras y Caretas constituyen una especie de síntesis programática de los planteos más amplios que serán desarrollados en otros medios. Véase «Los sillares de la raza», Caras y Caretas, no. 837 (17 de octubre, 1914); «La religión de la raza», Caras y Caretas, no. 839 (31 de octubre, 1914); «Patria y cultura», Caras y Caretas, no. 840 (7 de noviembre, 1914); «El nuevo nacionalismo argentino», Caras y Caretas, no. 841 (14 de noviembre, 1914); «Filosofía de la argentinidad», Caras y Caretas, no. 842 (21 de noviembre, 1914); «Cultura y energía», Caras y Caretas, no. 843 (28 de noviembre, 1914); «La justicia de la raza», Caras y Caretas, no. 849 (9 de enero, 1915); «La tradición argentina», Caras y Caretas, no. 856 (27 de febrero, 1915). Posteriormente dedicará dos estudios más amplio sobre la cuestión: «Para una filosofía argentina», publicado en la Revista de Filosofía en enero de 1915 y «La formación de la raza argentina», conferencia dictada en el Instituto Popular de Conferencias dependiente del diario La Prensa, publicada luego en dicho matutino el 2 de septiembre de 1915 y que se inscriben en la pregunta por el sustrato histórico del país a la que dará forma definitiva hacia el fin de la guerra en su libro La evolución sociológica argentina. 
con Francia o Inglaterra, desde el punto de vista económico la posición que más le convenía a las élites locales era la neutralidad pues les permitiría seguir vendiendo los productos agropecuarios a sus clientes tradicionales ahora más necesitados que nunca de ellos. Incluso antes de que estallara la guerra, un editorial del diario La Tarde declaraba «hacemos íntimos votos por la paz pero si para ello resultaran inútiles todos los esfuerzos humanos, nuestro país venderá a precios excepcionales sus stocks de trigo, maíz, avena, carne, etc.» ${ }^{16}$. En sintonía con esta mirada, y a pesar de la existencia de una cierta congoja por el destino Europa, en las semanas iniciales de la contienda es posible advertir la emergencia de un difuso pero palpable nacionalismo económico, por lo general, tramado con una defensa de la neutralidad estatal. Desde esta perspectiva, la Gran Guerra era presentada como una ocasión estupenda para el porvenir de la economía nacional. El diario La Prensa resumía este decálogo de pragmatismo económico con estas palabras: «aunque en el orden de la solidaridad humana siga conmoviéndose hondamente el espíritu argentino, no existe ya inconveniente en declarar que los efectos económicos de la magna tragedia han de obrar de una manera favorable en el valor de nuestra producción» ${ }^{17}$.

Si bien desde 1913 la economía argentina evidenciaba algunos problemas -que al día de hoy los historiadores debaten si se debían al estallido de la guerra en los Balcanes o bien respondían a problemas endógenos-, y a pesar de que el inicio de las hostilidades produjo graves complicaciones en el ámbito comercial y financiero, los periódicos locales mostraban un aplomado optimismo respecto de las consecuencias económicas que el conflicto podía ocasionar en Argentina. A raíz del paquete de medidas económicas tomadas por el gobierno de Victorino de la Plaza, el diario La Prensa afirmaba que «la República Argentina

16 «La guerra», La Tarde [Buenos Aires], 31 de julio, 1914, 1.

17 «Oportunidad para el desarrollo de la viticultura», La Prensa [Buenos Aires], 18 de agosto, 1914, 5. Por su parte, La Nación sostenía: «Nuestro fondo de riqueza lo constituyen las carnes y los cereales, alimentos que en los desarrollos eventuales del conflicto son elementos tan decisivos como el poder militar o la fuerza financiera. Ellos han de pagarse a buen precio». «Los efectos de la guerra», 1 de agosto, 1914, 8 . es uno de los pueblos de la tierra que, por causas y circunstancias varias, ha de experimentar sus repercusiones ruinosas en menor escala» ${ }^{18}$. Por ello llamaba a mantener la calma y a dejar de lado ese «estado de sobreexcitación irreflexiva» que se había apoderado de la opinión pública, el cual «deberá ceder a la observación razonada, a cuya luz se descubre que por poderoso que sea el contagio de la inmensa perturbación del viejo mundo, sus expansiones exteriores no alcanzarán a comprometer, en lo más mínimo, los destinos de la República Argentina». Europa, socio comercial predilecto de la Argentina agroexportadora y principal inversor en el país, es ahora un continente asediado por el flagelo de la guerra, lo que obliga a una mirada introspectiva sobre las potencialidades de Argentina para atravesar la crisis económica. Aunque insertas en la trama discursiva y conceptual del liberalismo económico, este tipo de discursos revela una marcada tendencia a prestar mayor atención a las necesidades del mercado nacional y a lo que más imprecisamente se denomina como «nuestro orden económico, comercial, financiero y monetario», «nuestros propios intereses» $\mathrm{O}$ «nuestros recursos» ${ }^{19}$.

18 «Repercusión de la guerra en la Argentina», La Prensa [Buenos Aires], 2 de agosto, 1914, 6. Las medidas aprobadas por el gabinete del Dr. De la Plaza en la reunión del domingo 2 de agosto fueron: un decreto de feriado cambiario y bancario del 3 al 8 de agosto; una moratoria interna por treinta días; el cierre de la Caja de Conversión; la autorización a la Caja de Conversión a redescontar documentos comerciales del Banco de la Nación; facultar a las legaciones para recibir el pago en oro de los deudores de firmas argentina para luego remitirlo al país y la prohibición de exportar oro, trigo y harina. Véase Ricardo Weinmann, Argentina en la Primera Guerra Mundial. Neutralidad, transición política y continuismo económico (Buenos Aires: Biblos - Fundación Simón Rodríguez, 1994), 39-41.

19 Si bien en la coyuntura de la guerra hubo una mayor demanda de intervención del Estado en la economía, los diarios más tradicionales como La Nación recordaban que ese tipo de medidas «entrañan una verdadera intervención dictatorial en el manejo libre de la vida comercial y financiera», solo justificable por la gravedad de la situación. «El momento financiero», La Nación [Buenos Aires], 4 de agosto, 1914, 8. Ese intervencionismo estatal será seguido muy atentamente por los periódicos más tradicionales para evitar que se produzcan «excesos» por parte del Estado. Por ejemplo, ante la medida de alojar en el Hotel de Inmigrantes a las personas que se encuentren en la indigencia por falta de trabajo, La Prensa se opuso duramente recordando que «hasta ahora, el concepto de la misión del Estado entre nosotros, ha sido el garantizar y facilitar el libre desenvolvimiento de las actividades, como requisito indispensable para contribuir al progreso nacional». «El gobierno y los obreros sin trabajo», La Prensa [Buenos Aires], 21 de agosto, 1914, 8. 
El tono optimista imperante en muchas de esas intervenciones, que contrasta con la mirada sombría sobre los destinos de Europa, suele ir acompañado de una imagen de la Gran Guerra como una situación que Argentina debería aprovechar. En este sentido, el diario La Razón, en su editorial del lunes 3 de agosto, llamaba al pueblo argentino a cumplir con sus deberes en «la defensa y conservación de sus propios intereses» e insistía en el carácter transitorio de la situación creada por los acontecimientos en Europa, que tal vez obligaban a realizar algunos esfuerzos y privaciones que luego de finalizada la guerra tendrían su recompensa:

No vendrá ahora el oro para «negocios» pero vendrá luego para pagar nuestros productos. Entretanto debemos bastarnos a nosotros mismos y es en esto en lo que consiste la transición que, repetimos, será momentánea, porque la misma lucha europea creará las nuevas necesidades de colocación proficua de los capitales $y$, sobre todo, las necesidades perentorias de nuestra producción ${ }^{20}$.

En coincidencia con un pronóstico bastante extendido según el cual las operaciones militares no se prolongarían más allá de la Navidad de 1914, la guerra era presentada como una situación anómala que si bien producía algunas complicaciones para un modelo económico excesivamente dependiente del exterior, abría, a su vez, la posibilidad de colocar en mejores condiciones los productos argentinos en una Europa necesitada de alimentos y de materias primas pues, como recordaba un editorial de La Prensa, en tiempos de guerra «el oro es esclavo del trigo» ${ }^{21}$.

Este tipo de opiniones adquiere un tono casi programático en varios editoriales del diario $L a$ Prensa y se encuentra brillantemente plasmado en «Los engranajes comerciales», publicado a mediados de agosto de 1914. Allí se afirma: «La guerra europea debemos aprovecharla en nuestro país como una valiosa experiencia, a fin de poder impulsar la economía nacional, más que como una exclusiva enseñanza militar». Para ello exigía a los gobernantes y a las clases dirigentes el estudio «de los factores de la economía argentina, a fin de orientarnos hacia el medio exacto de

20 «Deberes populares», La Razón [Buenos Aires], 3 de agosto, 1914, 4.

21 «El cataclismo europeo. Sus consecuencias económicas», La Prensa [Buenos Aires], 7 de septiembre, 1914, 5. las necesidades colectivas» ${ }^{22}$. Ante todo, se imponía la necesidad de volver a reactivar el flujo de capitales, detenido por el estallido de la guerra, y continuar dinamizando la producción teniendo en cuenta las necesidades de los mercados europeos pero sin olvidar el mercado interno para evitar el alza de precios y los conflictos sociales.

Sin embargo, la puesta a prueba del modelo agroexportador y las diferentes perturbaciones económicas y financieras ocasionadas por el estallido de la guerra no se tradujeron de inmediato en un cuestionamiento sobre la excesiva dependencia externa de la economía nacional. Por el contrario, en la gran mayoría de los diarios de Buenos Aires existen claros indicios de un marcado orgullo de la condición de país exportador de alimentos y materias primas. A mediados de agosto, una noticia sobre la elección del novillo campeón en la exposición anual de la Sociedad Rural Argentina de 1914 fue la ocasión perfecta para desplegar un juego de espejos entre los campos argentinos, que producen esas riquezas agropecuarias gracias al trabajo de su cosmopolita población, y los ejidos de la vieja Europa, convertidos en campos de batalla y sustraídos de sus tradicionales labores productivas. Para el anónimo comentarista del diario La Mañana, frente al estallido de las hostilidades en Europa, Argentina actuaba como aquel campesino retratado por Émile Zola en su novela La Debácle, que continúa trabajando su campo mientras a sus espaldas se destrozan los ejércitos en la batalla de Sedán durante la guerra franco-prusiana ${ }^{23}$.

Ahora bien, más allá de los debates en torno al plano económico, los primeros días de la guerra estuvieron marcados por las movilizaciones callejeras, la febril demanda de información y una enorme expectativa sobre el decurso de la contienda en la que, sin lugar a dudas, tenía una enorme importancia el alto porcentaje de inmigrantes que residían en Argentina y, en particular, en Buenos Aires. Recordemos que entre 1869 y 1914, la población del país había trepado de 1.737 .000 a 7.885.000 habitantes y en el mismo periodo Buenos Aires pasó de 187.000

\footnotetext{
22 «Los engranajes comerciales», La Prensa [Buenos Aires], 17 de agosto, 1914, 7.

23 «El novillo», La Mañana [Buenos Aires], 25 de agosto, 1914, 1.
} 
a 1.575.000 habitantes. Dicho crecimiento fue el resultado de la participación argentina en las corrientes de migración atlántica, lo cual explica que en vísperas de la Primera Guerra Mundial aproximadamente el 30\% de los habitantes del país fueran extranjeros, un porcentaje que aumentaba notablemente en las grandes ciudades como Buenos Aires donde cerca del 50\% de la población estaba constituida por extranjeros ${ }^{24}$.

Los comentarios en torno al comportamiento de esa variopinta masa de extranjeros que habitaban en la ciudad permiten reevaluar algunos elementos destacados del pasado nacional como la inmigración y trazar una reivindicación del cosmopolitismo considerado como un elemento característico de la cultura naciona ${ }^{25}$. Es por esto que la cruda realidad de la guerra causada, entre otras cosas, por los odios nacionalistas que signaban Europa contrasta con la presencia en Buenos Aires de miles de ciudadanos de las naciones beligerantes los cuales han sabido convivir en un clima de paz y de respeto mutuo. En este sentido, el diario $L a$ Nación comentaba con cierta jactancia:

Es de notarse con complacencia: entre esos enemigos que allá empuñan las armas los unos contra los otros, no se ha producido aquí ninguna salida de tono. Todos van en busca de sus noticias, las leen codeándose, con entusiasmo o grave silencio, según lo que ellas dicen al alma de cada cual, y se retiran comentándolas con

24 Véase Gino Germani, Política y sociedad en una época en transición. De la sociedad tradicional a la sociedad de masas (Buenos Aires: Paidós, 1962), 179-216; AA.WV, «La ciudad en el Censo Nacional de 1914. Tercer Censo General», Población de Buenos Aires, no. 8 (2008): 83-94. En 1914 los porcentajes de la población extranjera según su origen eran los siguientes: italianos (40,6\%), españoles (36,3\%), franceses (3,5\%), británicos (1,2\%), suizos $(0,6 \%)$, alemanes $(1,1 \%)$, rusos $(4,1 \%)$, austro-húngaros $(1,7 \%)$, sirio-libaneses (2,8\%). VicenteVázquezPresedo, El caso argentino: migración de factores, comercio exterior y desarrollo, 1875-1914 (Buenos Aires: Eudeba, 1971), 94.

25 «La particular contextura de la sociedad argentina, hija de un heteróclito cosmopolitismo, hace que sintamos vivamente las consecuencias de la espantosa tragedia. Conviven con nosotros, aportando a nuestro progreso su esfuerzo, elementos de todas las naciones en lucha: ingleses, franceses, alemanes, austríacos, belgas. Han formado hogares en nuestro país, hogares en que ha de sentirse hoy la vibración trágica de sus patrios lares, avivando el hondo amor por la nostalgia y acentuada exaltación del espíritu de raza por la solemnidad del momento. Multitud de argentinos, hijos de estos hogares, sentirán por contaminación del espíritu familiar, las vibraciones del alma de sus padres. Por esto, la tragedia europea repercute entre nosotros con tal variedad de matices emocionales, sacudiendo el espíritu argentino en las formas más diversas». «La guerra en el continente europeo», La Prensa [Buenos Aires], 5 de agosto, 1914, 7. discreta continencia de quienes se sienten en un lugar de hospitalidad común a todos, verdadero campo neutral donde los aires de buena paz suavizan el calor de los espíritus erguidos por la lucha. Mañana, muchos de ellos habrán partido para sus respectivos países, adonde el deber ante el peligro de la patria los llama y se encontrarán quizás frente a frente en el violento conflicto de la cólera guerrera, buscándose con saña el corazón enemigo; pero entretanto, aquí, en el tranquilo suelo de América nada los empuja a unos contra otros y leen codeándose y respetándose, sin violencia de ánimo, las noticias que anuncian el principio de la guerra en sus respectivos pueblos ${ }^{26}$.

A la luz del estallido de la guerra, la autoafirmación de algunos de los rasgos más sobresalientes de la reciente historia nacional produce una mirada satisfecha sobre la experiencia argentina que puede vanagloriarse de haber sabido conjugar, en el marco de un proceso de modernización vertiginoso, un acelerado crecimiento económico y material con una evolución histórica relativamente pacífica. Esto ocurrió así ya que, al menos desde su conformación como Estado nacional, no había intervenido en ningún conflicto bélico internacional y había dejado atrás el fantasma de la guerra civil que la acompañara durante gran parte del siglo XIX.

En las páginas de los diarios y las revistas de Buenos Aires, la imagen de la Argentina pacífica del «crisol del razas» emerge como el epítome de una representación del Estado y del pueblo argentino como esencialmente cosmopolita, pacífico y tolerante. Da paso a una alabanza de las libertades democráticas imperantes en el país y revela de qué manera ciertos valores universales como la libertad y la democracia podían ser reivindicados simultáneamente por los defensores locales de la francofilia y, a su vez, por aquellos interpretes de la guerra más abocados a reevaluar las características centrales de la identidad nacional:

[...] esta tranquilidad de Buenos Aires es algo honroso para el país y algo que tiene que ratificarnos en el culto a la libertad, pues ella es la fuerza que une sin ahogar. No es el «yo» imperial que acaba de estallar en Europa ni una fórmula de intereses; es la libertad buena para todos $[\ldots]^{27}$.

26 «La conflagración europea. Su influencia en nuestro país», La Nación [Buenos Aires], 5 de agosto, 1914, 9. En el mismo sentido véase «La actitud de Buenos Aires», La Nación, 5 de agosto, 1914, 8 y «Repercusión del conflicto en la Argentina», La Razón [Buenos Aires], 4 de agosto, 1914, 2.

27 «Libertad y respeto», La Mañana [Buenos Aires], 4 de agosto, 1914, 1. 
La paz, junto a las posibilidades de progreso que el suelo argentino brindaba a esos miles de europeos que habían cruzado el Atlántico en busca de mejores perspectivas y cuyos destinos se verán truncados por el estallido de la guerra, es el escenario desde el que la prensa porteña coteja sus diferencias con el Viejo Continente sumido en la cruda realidad de la guerra y se autorreconoce positivamente en su experiencia pacífica reciente que había posibilitado su notable progreso económico y social.

Esa progresiva toma de distancia respecto del magisterio europeo que impulsa el estallido de la guerra y el retorno a los debates sobre la identidad nacional produjeron una serie de modificaciones en la escala del evolucionismo local, dando paso a una dura autocrítica sobre el lugar privilegiado que Europa había ocupado en el imaginario de las élites argentinas y, en particular, sobre el apego acrítico de estas a la cultura europea. A pocas semanas de iniciado el conflicto, contraponiendo nuevamente la realidad del continente europeo con el panorama que se vivía en Buenos Aires, un editorial de La Mañana ensayaba una despiadada impugnación del europeísmo local que, en cierto sentido, hilvana varios de los elementos del debate señalados anteriormente:

Los despachos relativos a la guerra han de hacer mucho bien a nuestro pueblo. Desde luego, han de curarle por siempre de la inocente manía de referir todas las conquistas del progreso y de la cultura a los países del viejo mundo. Han de afirmar su optimismo vacilante sobre la urbanidad de nuestras multitudes y sobre otras ignoradas excelencias de la patria. Se ha convenido en decir: nosotros no estamos todavía a la altura de las naciones de Europa. Perfectamente, Dios quiera que no lo estemos nunca ¡La cultura de los países del Viejo Mundo! Apenas si hay lugar común tan falso. Nosotros hablamos de la cultura europea en un sentido absoluto. Los últimos despachos relativos a la guerra nos abren los ojos sobre nuestra ingenuidad. Ellos nos permiten asistir al mentís lanzado por un pueblo orgulloso y fuerte a su decantada civilización. Escenas semejantes a las ocurridas en dicho pueblo no presenciaron jamás los países menores de este continente ni en las sombrías épocas de dictadura y de guerra civil ${ }^{28}$.

28 «Un pueblo civilizado», La Mañana, 12 de agosto, 1914, 1. En sentido inverso, la progresiva impugnación de la influencia europea en Argentina posibilitará también una crítica sobre la imagen que Europa tenía de Sudamérica como la tierra del «atraso» y la «barbarie» pintoresca pues, como recordaba Leopoldo Lugones en una crónica escrita desde París a comienzos de julio de 1914, «para
El progresivo desplazamiento de esa mirada «ingenua» sobre las bondades y virtudes de Europa junto al renovado interés por la identidad y la cultura nacional irán conformando en un amplio espectro de la prensa local un mayor sentimiento de pertenencia que se traducirá en una búsqueda por parte de esos «países menores» del continente sudamericano de un diálogo en igualdad de condiciones con las naciones europeas y que halló en la firma del Tratado del A.B.C. uno de sus momento fundacionales ${ }^{29}$. En gran medida, esas nuevas pretensiones eran el resultado del efecto catalizador que el inicio de la Primera Guerra Mundial había producido sobre la identidad nacional y anteceden en varios años a los preceptos de la autodeterminación nacional propugnada por el presidente de los Estados Unidos, Woodrow Wilson.

\section{Consideraciones finales}

El estallido de la Gran Guerra produjo una enorme repercusión en Buenos Aires y desató una gran expectativa en el seno de la opinión pública porteña. En su dimensión más inmediata, los diferentes alineamientos de la prensa local estuvieron, al menos en parte, condicionados por la procedencia de la información, la cual estaba sometida a fuertes manipulaciones en favor de los aliados de la Entente gracias al monopolio de la agencia Havas sobre el mercado sudamericano de comunicaciones y al control por parte de las compañías

Europa seguimos siendo indios de estampa». Leopoldo Lugones, «La viga en el ojo», La Nación [Buenos Aires], 10 de agosto, 1914, 4-5. En análogo sentido, El Nacional afirmaba que en las principales capitales del Viejo Continente «se suponían que en Buenos Aires y demás ciudades argentinas, sus habitantes andaban en cueros, con plumas en la cabeza y lanza en ristre». «Turf», El Nacional [Buenos Aires], 14 de agosto, 1914, 1.

29 El llamado Pacto del ABC, cuyo nombre oficial era Pacto de No Agresión, Consulta y Arbitraje, fue firmado en Buenos Aires, el 25 de mayo de 1915, por los cancilleres de Argentina, Brasil y Chile, de allí su nombre. El tratado reconocía su origen en la Conferencia de Niagara Falls, que tuvo lugar entre el 21 de abril y el 30 de junio de 1914. En ella, los miembros del ABC propusieron una mediación diplomática ante el recrudecimiento del conflicto entre México y los Estados Unidos, luego del incidente de Tapinco y la ocupación norteamericana de Veracruz. Para un análisis detallado véase Beatriz Solveira de Baez. «El ABC como entidad política: un intento de aproximación entre la Argentina, Brasil y Chile a principios de siglo», Ciclos en la historia, la economía y la sociedad, no. 2 (1992): 157-183, y su libro La Argentina, el ABC y el conflicto entre México y los Estados Unidos (1913-1916) (Córdoba: Centro de Estudios Históricos, 1994). 
británicas de cables submarinos de los principales medios de transmisión de la información. Sin embargo, más allá de la capacidad para formar opinión que pudieron haber tenido estas noticias procedentes de Europa, los diferentes alineamientos de la opinión pública local no pueden comprenderse únicamente por esa manipulación informativa. Los estrechos vínculos económicos, políticos, demográficos y culturales que ligaban a Argentina con Europa habían forjado, con anterioridad al estallido de la guerra, diversas afinidades con algunos de los países contendientes que también permiten analizar los posicionamientos de los diarios porteños frente a la Gran Guerra.

Junto a esos diferentes posicionamientos, se ha constatado la emergencia de una serie de interpretaciones que caracterizaron a la conflagración europea como un verdadero «suicidio de Europa». En las páginas de las publicaciones periódicas de Buenos Aires, ese temprano diagnóstico de la guerra como una crisis civilizatoria dio lugar a una serie de reflexiones sobre el legado europeo en Argentina y a un interrogante sobre la identidad nacional. Como en un juego de espejos, el estallido de la Gran Guerra produce una mirada introspectiva que permite reevaluar positivamente ciertos elementos del pasado nacional reciente. En primer lugar, la condición de país agroexportador pues, a pesar de la existencia de una cierta congoja por el destino Europa, en las semanas iniciales de la contienda es posible advertir la emergencia de un nacionalismo económico, por lo general tramado con una defensa de la neutralidad estatal. Desde esta perspectiva, la guerra europea era presentada como una ocasión estupenda para el porvenir de la economía nacional. Es por ello que, más allá de las simpatías con Francia o Inglaterra, desde el punto de vista económico la posición que más convenía a las élites locales era la neutralidad pues les permitiría continuar vendiendo los productos agropecuarios a sus clientes tradicionales ahora más necesitados que nunca de ellos.

En segundo lugar, la Gran Guerra operó como un revitalizador de un nacionalismo cosmopolita que reivindicaba la experiencia del «crisol de razas» y que, si bien no rechazaba de plano la influencia de la cultura europea, proponía la necesidad de adaptarla al medio local. En este sentido, los diferentes discursos que ponderaron el correcto comportamiento de los connacionales de los países combatientes que residían en Buenos Aires no solo dieron lugar a una revalorización de la inmigración europea y el cosmopolitismo sino también a un tercer elemento constitutivo de ese nacionalismo cosmopolita: el pacifismo. De esta manera, esa representación de la Argentina pacífica del «crisol de razas» será el epítome de una imagen del Estado y del pueblo argentino que emergerá en tiempos de la Gran Guerra como el resultado de un renovado interrogante sobre la cuestión nacional.

Por último, este análisis permite realizar un señalamiento de tipo metodológico en relación con cierta tendencia de la historiografía a lanzar una mirada rápida sobre los inicios de la Gran Guerra para concentrarse decididamente en la conflictiva coyuntura que jalona gran parte del año de 1917. Observar la «instantánea» que arroja ese particular momento de las repercusiones de la guerra en Buenos Aires en detrimento de una perspectiva de largo plazo es una opción arriesgada ya que puede llevar a considerar como novedosas algunas interpretaciones de la guerra -la guerra como un choque entre la «civilización francesa» y la «barbarie alemana»- que ya estaban presentes desde los primeros meses de conflicto, en particular luego de la invasión y ocupación alemana de Bélgica y de los departamentos de la frontera francesa en el verano europeo de 1914. Lo mismo ocurre con lo que la historiografía que ha examinado el impacto de la Gran Guerra en las reflexiones sobre la identidad nacional ha dado en llamar el «nacionalismo aliadófilo» ${ }^{30}$, basado en el cosmopolitismo resultante del «crisol de razas» de la Argentina liberal, cuyos principales rasgos ya estaban presentes en la prensa porteña desde el inicio mismo de la Gran Guerra.

\section{Bibliografía}

\section{Fuentes primarias}

Diarios

El Nacional

«Turf». El Nacional [Buenos Aires], 14 de agosto, 1914, 1.

30 Cf. Tato, «Nacionalismo», 59 y «La disputa», 248. 
La Mañana

«La guerra».La Mañana [Buenos Aires], 2 de agosto, $1914,1$.

«Libertad y respeto». La Mañana [Buenos Aires], 4 de agosto, 1914, 1 .

«Un pueblo civilizado». La Mañana, 12 de agosto, $1914,1$.

«El novillo». La Mañana [Buenos Aires], 25 de agosto, 1914, 1.

\section{La Nación}

«Los efectos de la guerra». La Nación [Buenos Aires], 1 de agosto, 1914, 8.

«El momento financiero». La Nación [Buenos Aires], 4 de agosto, 1914, 8.

«La conflagración europea. Su influencia en nuestro país». La Nación [Buenos Aires], 5 de agosto, $1914,9$.

«La actitud de Buenos Aires». La Nación, 5 de agosto, 1914,8 .

Lugones, Leopoldo. «La viga en el ojo», La Nación [Buenos Aires], 10 de agosto, 1914, 4-5.

«Informaciones oficiales. Familias argentinas en Europa». La Nación [Buenos Aires], 15 de agosto, $1914,9$.

Gil, Martín. «Impresiones». La Nación, 17 de agosto, 1914,5 .

«Tribulaciones de los argentinos en Europa». $L a$ Nación [Buenos Aires], 8 de septiembre, 1914, 9.

\section{La Prensa}

«Guerra en el continente europeo». La Prensa [Buenos Aires], 2 de agosto, 1914, 7.

«Repercusión de la guerra en la Argentina». La Prensa [Buenos Aires], 2 de agosto, 1914, 6.

«La guerra en el continente europeo». La Prensa [Buenos Aires], 5 de agosto, 1914, 7.

«Los engranajes comerciales». La Prensa [Buenos Aires], 17 de agosto, 1914, 7.

«El gobierno y los obreros sin trabajo». La Prensa [Buenos Aires], 21 de agosto, 1914, 8.

Ingenieros, José. «La formación de la raza argentina». La Prensa [Buenos Aires], 3 de septiembre, 1915, 6-7.

«El cataclismo europeo. Sus consecuencias económicas». La Prensa [Buenos Aires], 7 de septiembre, 1914, 5 .

«Oportunidad para el desarrollo de la viticultura». La Prensa [Buenos Aires], 18 de agosto, 1914, 5.
La Razón. Diario de la tarde

«Deberes populares». La Razón [Buenos Aires], 3 de agosto, 1914, 4.

«Repercusión del conflicto en la Argentina». La Razón [Buenos Aires], 4 de agosto, 1914, 2.

La Tarde

«La guerra». La Tarde [Buenos Aires], 31 de julio, $1914,1$.

Tribuna

«La Guerra». Tribuna [Buenos Aires], 6 de agosto, 1914, 2.

Revistas

Caras y Caretas

Ingenieros, José. «El suicidio de los bárbaros». Caras y Caretas [Buenos Aires], no. 829, 22 de agosto, 1914.

Ingenieros, José. "Los sillares de la raza». Caras y Caretas, no. 837 (17 de octubre, 1914).

Ingenieros, José. «La religión de la raza». Caras y Caretas, no. 839 (31 de octubre, 1914).

Ingenieros, José. «Patria y cultura». Caras y Caretas, no. 840 (7 de noviembre, 1914).

Ingenieros, José. «El nuevo nacionalismo argentino». Caras y Caretas, no. 841 (14 de noviembre, 1914).

Ingenieros, José. «Filosofía de la argentinidad». $\mathrm{Ca}$ ras y Caretas, no. 842 (21 de noviembre, 1914).

Ingenieros, José. «Cultura y energía». Caras y Caretas, no. 843 (28 de noviembre, 1914).

Ingenieros, José. «La justicia de la raza». Caras y $\mathrm{Ca}$ retas, no. 849 (9 de enero, 1915).

Ingenieros, José. «La tradición argentina». Caras y Caretas, no. 856 (27 de febrero, 1915).

\section{Revista de Filosofía}

Ingenieros, José. «Para una filosofía argentina». $R e-$ vista de Filosofía (enero de 1915): 1-6.

\section{Mundo Argentino}

Pandolfini, Carmen S. De. "Charla femenina». Mundo Argentino no. 189 (19 de agosto, 1914).

Pandolfini, Carmen S. De. "Charla femenina». Mundo Argentino no. 190 (26 de agosto, 1914).

\section{Fuentes secundarias}

AA.vv. «La ciudad en el Censo Nacional de 1914. Tercer Censo General». Población de Buenos Aires, no. 8 (2008): 83-94. 
Bertoni, Lilia Ana. Patriotas, cosmopolitas y nacionalistas. La construcción de la nacionalidad argentina a fines del siglo XIX. Buenos Aires: FCE, 2001.

Compagnon, Olivier. «'Si loin, si proche...' La Première Guerre mondiale dans la presse argentine et brésilienne». En L'envers de la médaille. Guerres, témoignages et représentations, editado por Jean Lamarre y Magali Deleuze, 77-91. Québec: Les Presses de l'Université Laval, 2007.

Compagnon, Olivier. L'adieu à l'Europe. L'Amérique latine et la Grande Guerre (Argentine et Brésil, 1914-1939). París: Fayard, 2013.

Degiovanni, Fernando. «Nacionalismo de mercado y disidencia cultural: La cultura argentina de Ingenieros». Los textos de la patria. Nacionalismo, politicas culturales y canon en la Argentina, 215320. Rosario: Beatriz Viterbo, 2007.

Devoto, Fernando. Nacionalismo, fascismo y tradicionalismo en la Argentina moderna. Una historia. Buenos Aires: Siglo xxi, 2006.

Gasparini, Sandra. Espectros de la ciencia. Fantasias científicas de la Argentina del siglo XIX. Buenos Aires: Santiago Arcos, 2012.

Germani, Gino. Politica y sociedad en una época en transición. De la sociedad tradicional a la sociedad de masas. Buenos Aires: Paidós, 1962.

Gramuglio, María Teresa. Nacionalismo y cosmopolitismo en la literatura argentina. Rosario: EMR, 2013.

Halperín Donghi, Tulio. Vida y muerte de la República verdadera (1910-1930). Buenos Aires: Ariel, 1999.

Ingenieros, José. Los tiempos nuevos. Reflexiones optimistas sobre la guerra y la revolución. Buenos $\mathrm{Ai}$ res: Cuneo, 1921.

Montserrat, Marcelo. «La mentalidad evolucionista: una ideología del Progreso». En La Argentina del Ochenta al Centenario, compilado por Gustavo Ferrari y Ezequiel Gallo, 785-818. Buenos Aires: Sudamericana-utdT, 1980.

Ministerio de Relaciones Exteriores y Culto, Argentina. «Decreto declarando la neutralidad de la República en el estado de guerra entre AustriaHungría, Servia, Rusia, Alemania, Inglaterra, Francia y Bélgica». En El libro azul. Documentos y actos de gobiernos relativos a la guerra en Europa, 4-6. Buenos Aires: Establecimiento Gráfico Enrique L. Frigueiro, 1919.

Payá, Carlos y Eduardo Cárdenas. El primer nacionalismo argentino en Manuel Gálvez y Ricardo Rojas. Buenos Aires: Peña Lillo, 1978.
Rossi, Luis Alejandro. «Los proyectos intelectuales de José Ingenieros desde 1915 a 1925: la crisis del positivismo y la filosofía en la Argentina». Revista de Filosofía, Cultura-Ciencias - Educación (edición facsimilar), 13-62. Bernal: unQUI, 1999.

Sánchez, Emiliano Gastón. «Ecos argentinos de la contienda europea. La historiografía sobre la Gran Guerra en la Argentina». Políticas de la $\mathrm{Me}$ moria. Anuario de investigación e información del CeDInCI, no. 13 (verano 2012/13): 163-169.

Solveira de Baez, Beatriz. «El ABC como entidad política: un intento de aproximación entre la Argentina, Brasil y Chile a principios de siglo». Ciclos en la historia, la economía y la sociedad, no. 2 (1992): 157-183.

Solveira de Baez, Beatriz. La Argentina, el ABC yel conflicto entre México y los Estados Unidos (1913-1916). Córdoba: Centro de Estudios Históricos, 1994.

Tato, María Inés. «Nacionalismo e internacionalismo en la Argentina durante la Gran Guerra». Projeto História, no. 36 (2008): 49-62.

Tato, María Inés. «La disputa por la argentinidad. Rupturistas y neutralistas durante la Primera Guerra Mundial». Temas de historia argentina $y$ americana, no. 13 (2008): 227-250.

Terán, Oscar. José Ingenieros: pensar la nación. Antología de textos. Buenos Aires: Alianza, 1986.

Terán, Oscar. Vida intelectual en el Buenos Aires finde-siglo (1880-1910). Derivas de la «cultura cientifica». Buenos Aires: FCE, 2008 [original 2000].

Vázquez Presedo, Vicente. El caso argentino: migración de factores, comercio exterior y desarrollo, 18751914. Buenos Aires: Eudeba, 1971.

Weinberg, Gregorio. La ciencia y la idea de progreso en América latina, 1860-1930. Buenos Aires: FCE, 1998.

Weinmann, Ricardo. Argentina en la Primera Guerra Mundial. Neutralidad, transición politica y continuismo económico. Buenos Aires: Biblos Fundación Simón Rodríguez, 1994.

Recepción: 29 enero 2014

Aprobación: 24 marzo 2014

\section{Cómo citar este artículo}

Gastón Sánchez, Emiliano. «La prensa de Buenos Aires ante "el suicidio de Europa". El estallido de la Gran Guerra como una crisis civilizatoria y el resurgimiento del interrogante por la identidad nacional». $M e-$ moria y Sociedad 18, no. 37 (2014): 132-146. http:// dx.doi.org/10.11144/Javeriana.mys18-37.lpba 